\title{
Epistemic Vices in Organizations: Knowledge, Truth, and Unethical Conduct
}

\author{
Christopher Baird ${ }^{1} \cdot$ Thomas S. Calvard $^{1}$ (i)
}

Received: 25 January 2018 / Accepted: 19 April 2018 / Published online: 30 April 2018

(c) The Author(s) 2018

\begin{abstract}
Recognizing that truth is socially constructed or that knowledge and power are related is hardly a novelty in the social sciences. In the twenty-first century, however, there appears to be a renewed concern regarding people's relationship with the truth and the propensity for certain actors to undermine it. Organizations are highly implicated in this, given their central roles in knowledge management and production and their attempts to learn, although the entanglement of these epistemological issues with business ethics has not been engaged as explicitly as it might be. Drawing on work from a virtue epistemology perspective, this paper outlines the idea of a set of epistemic vices permeating organizations, along with examples of unethical epistemic conduct by organizational actors. While existing organizational research has examined various epistemic virtues that make people and organizations effective and responsible epistemic agents, much less is known about the epistemic vices that make them ineffective and irresponsible ones. Accordingly, this paper introduces vice epistemology, a nascent but growing subfield of virtue epistemology which, to the best of our knowledge, has yet to be explicitly developed in terms of business ethics. The paper concludes by outlining a business ethics research agenda on epistemic vice, with implications for responding to epistemic vices and their illegitimacy in practice.
\end{abstract}

Keywords Epistemic vice $\cdot$ Virtue epistemology $\cdot$ Vice epistemology $\cdot$ Truth $\cdot$ Knowledge acquisition

\section{Introduction}

The politically contested nature of truth-claims and their manipulation via propaganda, ideology, and other forms of power, social construction, and knowledge production are a familiar mainstay of social scientific inquiry. In the twentyfirst century, however, a renewed set of debates and concerns is emerging around politics, the media, public relations (PR), and the public's problematic relationship with the truthwith phrases like 'alternative facts,' 'post-truth,' 'fake news,' and 'bullshit' being highlighted within academic and popular discourse (e.g., Ball 2017; D’Ancona 2017; Davis 2017; Paul 2017; Spicer 2017).

Organizations are and have always been heavily implicated in these issues. Knowingly or unknowingly, they take

Thomas S. Calvard

Thomas.calvard@ed.ac.uk

Christopher Baird

C.Baird@ed.ac.uk

1 University of Edinburgh Business School, 29 Buccleuch Place, Edinburgh EH8 9JS, UK up their own distinctive stances on knowledge production (Kilduff et al. 2011). Furthermore, at individual and collective levels, organizations struggle with learning processes (Argyris 2003), managing various types of knowledge and knowing (Cook and Brown 1999), and, most politically and ethically, sometimes end up playing games with the truth, producing and reproducing distinct forms of language and discourse (Mauws and Phillips 1995; Munro 2017; Phillips and Oswick 2012).

Despite these profound linkages between knowledge, truth, and organization, explicit acknowledgement of the entanglement between epistemology and ethics remains relatively under-explored (de Bruin 2013, 2015). In the same way that politics and ethics can be artificially separated by different researchers working at different levels of analysis and with different concerns (Parker 2003), epistemology is often regarded in non-ethical, analytical terms as part of a research methodology, or in terms of the cognition and information processing capacities of organizations. In philosophy too, epistemology has not always been traditionally concerned with ethics either, often restricting itself to 
analytical discussions of how justification, truth, and belief relate to definitions of knowledge (Battaly 2016).

For (business) ethicists, this widespread omission of epistemology from ethics and ethics from epistemology is both surprising and significant. Surprising given the general links between epistemological concerns, such as how we acquire knowledge, and ethical concerns, such as how we deliver fair hearings or deliberate on policy-making (e.g., Griffin 2011; Kidd et al. 2017). Significant because a failure to consider these epistemic-ethical relationships risks leaving the spread of ignorance and confusion inadequately theorized (Oreskes and Conway 2012), and fails to hold accountable those who disregard 'epistemic goods' such as 'truth,' 'justification,' 'wisdom,' and 'understanding' as responsible for the consequences of their attitudes and actions (Matheson and Vitz 2014). Consequently, a growing number of scholars have begun voicing these concerns (de Bruin 2013, 2015), calling for an 'epistemic ethics' (Buchanan 2009), and the development of theory around epistemic-ethical interfaces.

In this vein, the current paper draws on an important, under-examined contemporary development in epistemology that acts to lift the contrived divide between the epistemic and the ethical: virtue (and vice) epistemology. Virtue epistemology is the study of the cognitive character traits and attitudes that make us effective at, and responsible for, acquiring and transmitting epistemic goods (Battaly 2014). We can elucidate virtue epistemology by comparison with the more well-known field of virtue ethics. Just as Anscombe and modern virtue ethicists (e.g., MacIntyre 1981; Moore 2008; Solomon 1992) call for a shift in emphasis of ethical evaluation from acts onto agents - or, more specifically, to the character traits that constitute virtues and vices-virtue epistemologists argue that epistemic evaluation ought to shift its focus away from beliefs and onto agents and their cognitive characters (Montmarquet 1993; Zagzebski 1996).

What is significant about virtue epistemology from an ethical perspective is that many virtue epistemologists hold that we are, to varying degrees, responsible for our epistemic characters and conduct (e.g., Zagzebski 1996). In other words, epistemic agents can have both praiseworthy and/ or blameworthy psychologies. Blameworthy if, for example, a manager dismisses the value of true beliefs in favor of acquiring only comforting beliefs. This exemplifies the vice of epistemic insouciance (Cassam 2018). Praiseworthy if, for example, a successful executive acknowledges their own fallibility and attends to their cognitive limitations in a humble and respectable manner. This exemplifies the virtue of epistemic humility (Roberts and Wood 2007).

Accordingly, management scholarship has begun to recognize the potential of virtue epistemology to offer both a rich new paradigm for applied ethics and a new lens for contemplating organizational learning and knowledge acquisition. Following its introduction to management over the last 5 years (e.g., de Bruin 2013), virtue epistemology has begun to be applied to a range of business topics, including the global financial crisis (de Bruin 2014, 2015), managers' ethical decision-making (Rawwas et al. 2013), the ethics and practices of 'not knowing' (Crossman and Doshi 2015), as well as organizational culture (Wei Choo 2016). In sum, "Ideas of epistemic virtue and vice are," as Freeman (2015) notes, "an important addition to our way of thinking about business and ethics" (p. xi).

While we recognize these valuable contributions, we assert that one aspect in need of further development is a more thorough engagement with the conceptualization of epistemic vice. If epistemic virtues make us effective and responsible inquirers, epistemic vices make us deficient ones (Cassam 2016). They get in the way of what Hookway (2003) calls "effective and responsible inquiry" (p. 198). This is not to say that the epistemic vices are entirely absent from management literature (de Bruin 2015; Wei Choo 2016). They do, however, tend to remain under-theorized. Just as management literature more broadly can tend to sideline or overlook critical aspects of the "dark side of organization' (Linstead et al. 2014), virtue epistemology has tended to overlook the epistemic vices.

We therefore seek to contribute to virtue epistemology in business ethics by paying equal attention to important vices as well as just focusing on epistemic virtues. To this end, the current paper covers five key areas. First, we justify why ideas of epistemic virtue and vice matter at a fundamental level. Second, we introduce and develop theory from vice epistemology, a nascent but growing subfield of virtue epistemology which, to the best of our knowledge, has yet to be explicitly developed in terms of business ethics. Third, we make three arguments for why there is both space and need for a vice epistemology, particularly one sensitive to the context of business. Fourth, we review and outline a set of four major epistemic vices-malevolence, insouciance, hubris, and injustice-which we argue currently permeate many organizations. Finally, we conclude by outlining a business ethics research agenda on epistemic vices, with implications for organizations and managers responding to epistemic vices and their illegitimacy in practice.

\section{Epistemic Virtues and Vices}

To justify closer examination of vice epistemology and the epistemic vices in organizations, it is worth considering why the notions of epistemic virtue and vice matter at a fundamental level. To some extent, epistemic virtues and vices are merely a subset of, or counterpart to, better-theorized, moral (non-epistemic) virtues and vices. Both virtue ethics and virtue epistemology, for example, focus their evaluations on an agent; agents are considered at least partially responsible for their traits and resulting actions; virtues are excellences 
and vices are defects. However, there are also some key distinctions (Brady and Pritchard 2003).

To begin with, virtue and vice epistemology are primarily interested in the relations between virtue/vices and the cultivation of epistemic goods. Epistemic goods include such things as 'truth,' 'understanding,' 'wisdom,' and 'justification,' among others (Roberts and Wood 2003, p. 257). Epistemic virtues are specifically aimed at obtaining epistemic goods and not simply at doing the right thing. Although these aims might converge, they need not always do so and could perhaps even conflict (Annas 2003). In this way, the epistemic virtues and vices cannot simply be subsumed under the moral ones; they revolve around specific issues of truth, reasoning, self-reflection, knowledge, and knowing.

Epistemic virtues and vices also typically apply to different actions than non-epistemic virtues and vices. De Bruin (2013) gives the example of epistemic courage as compared with non-epistemic courage. Imagine, for instance, the reporter who enters a dangerous war-zone in order to undertake research. This 'courage' is the same courage required of the soldier too, albeit put to use for epistemic purposes. It does not thus qualify as epistemic courage. 'Facing the truth,' however, is a distinctly epistemic virtue, especially if it means adopting a belief that might harm oneself or one's organization. If a manager has long held the belief that their product or service is health-promoting yet evidence begins to suggest otherwise, it takes a certain kind of courage'epistemic courage' - to confront that knowledge and revise their prior beliefs.

Finally, while it is the case that some moral and epistemic virtues and vices have fairly close correspondences-for example, morally or epistemically, we can speak of someone as being cowardly or courageous; malevolent or benevolent; generous or miserly - others have no obvious moral equivalent at all. Distinctively epistemic-ethical orientations might include inquisitiveness, gullibility, or high levels of cynicism.

In sum, epistemic virtues and vices are importantly and discernibly different from non-epistemic virtues and vices because they aim at different ends; apply to different kinds of actions; and can have no clear non-epistemic counterpart. Having established these broader differences between virtue ethics and virtue epistemology, we now consider vice epistemology and the epistemic vices in more detail.

\section{Vice Epistemology and Conceptualizing Vices of the Mind}

We have defined virtue epistemology above as the study of the cognitive character traits and attitudes that make us effective at, and responsible for, acquiring or transmitting epistemic goods (Battaly 2014). By contrast, vice epistemology is interested in those cognitive character traits and attitudes which obstruct the effective and responsible acquisition or transmission of epistemic goods-epistemic vices, or what Zagzebski (1996) calls 'vices of the mind' (Cassam 2016).

Broadly, Kidd (2017) notes that vice epistemology is devoted to three sorts of issues: first, to foundational issues concerning the nature and structure of epistemic vices; second, to studies of specific epistemic vices, such as epistemic malevolence (Baehr 2011), and other vices we examine below; and third, to applied vice epistemology, which explores how epistemic vices manifest in specific contexts, practices, systems, and communities. In the current paper, we continue to build on and extend these conceptual and applied aspects of vice epistemology by highlighting their importance to the cognition and conduct of organizational actors. For a thorough discussion of virtue epistemology and organization, see de Bruin (2013).

Before we examine and extend a range of epistemic vices to organizations, it is important to clarify what we mean by epistemic vice. The historical and contemporary literature on epistemic vice emphasizes two key ways in which an agent's cognitive qualities may be characterized as epistemically vicious. They either (1) produce bad epistemic ends - falsehoods, incomprehension, or ignorance, for example. Here, epistemic vices get their vicious quality solely from the negative epistemic ends they produce. Or (2) they involve bad epistemic motives - cowardice, close-mindedness, or insouciance, for example. Here, bad epistemic ends are not sufficient for epistemic vice. Epistemic vices get their vicious quality by also involving bad epistemic motives for which an agent can be considered blameworthy for possessing (Battaly 2014). Each conceptualization corresponds to one of two main schools of thought in contemporary vice epistemology - those are vice-reliabilism in the case of (1) and vice-responsibilism in the case of (2) (Code 1987).

When epistemic ends or effects are all that matters, this conceptualization of epistemic vice is known as vice-reliabilism. For vice-reliabilists (e.g., Greco 1999; Sosa 1980), vices get their negative value by the bad epistemic ends they consistently produce, nothing more. Vice-reliabilists contend that epistemic vices are reliable dispositions that produce more false beliefs than true ones. These dispositions can be cognitive character traits, cognitive skills, or even hardwired faculties--for reliabilists, they all count as epistemic vices so long as they generate bad epistemic ends. In other words, reliabilist epistemic vices do not need to be acquired traits or motives; we can be born with them. Epistemic vices in this view might thus include more or less hard-wired (dis) abilities such as poor vision, hearing problems, or Alzheimer's disease, all of which reliably produce bad epistemic ends. ${ }^{1}$ Unsurprisingly, vice-reliabilism does not account for

\footnotetext{
${ }^{1}$ Reliabilist epistemic virtues, on the other hand, might include cognitive faculties such as '20/20 vision,' 'acute hearing,' or 'eidetic memory,' all of which reliably produce good epistemic ends. Virtue-
} 
the ethical implications of epistemic issues, since agents have no control over the particular faculties Mother Nature provides them with. While vice-reliabilism offers a valuable contribution to contemporary issues in epistemology, we do not find it useful for the purposes of the current paper, which seeks to explore epistemic-ethical interfaces among organizational agents. Thus, when we refer to vice epistemology and the epistemic vices, we are not doing so in the reliabilist tradition.

By contrast, vice-responsibilism argues that producing bad epistemic effects is insufficient for vice (Battaly 2014). Epistemic vice also demands a blameworthy psychology. For vice-responsibilists (e.g., Zagzebski 1996; Fricker 2007), vices get their negative value not simply by producing bad epistemic ends, but by also involving bad motivations and other blameworthy features of an agent's psychology. If an agent produces bad epistemic effects through no fault of their own (for example, their memory deteriorates with age), this is not sufficient for epistemic vice in the responsibilist tradition. If, however, an agent possesses bad epistemic motives, such as caring only about obtaining comforting beliefs (and not true ones), or caring only about themselves (and not others), then that agent may rightfully be attributed epistemic vice, provided they have some control over developing their cognitive traits (Battaly 2014). Epistemic vices in this view might thus include cognitive character traits such as a company director's dogmatism or a male manager's prejudice toward female employees as potential knowers. Both of these agents merit blame for the resulting failures and injustices of their epistemic character, so long as they have had some control over its development. ${ }^{2}$

As vice epistemologists correctly emphasize, viceresponsibilists must exercise prudence when charging agents with epistemic vice (Kidd 2016). Virtue and vice theorists have long argued that our characters-moral and epistemic - are formed through processes of acculturation, repetitive practice, and habituation (e.g., Arjoon 2000; MacIntyre 1981). In this way, agents develop attitudes, dispositions, and sensibilities over time through processes of socialization. Responsibility for epistemic virtues and vices is therefore likely to vary according to the epistemic environments

\section{Footnote 1 (continued)}

reliabilists contend that epistemic virtues are reliable dispositions that produce more true beliefs than false ones.

${ }^{2}$ Responsibilist epistemic virtues, on the other hand, might include an executive's 'open-mindedness' to considering alternative ideas when it is appropriate to do so, or a 'love of knowledge' that encourages evidence-based practices within an organization. These agents merit praise for their epistemic characters, provided they have some control over its development. Virtue-responsibilists contend that epistemic virtues are cognitive character traits that produce good epistemic ends and that an agent is praiseworthy for possessing. and circumstances agents find themselves in (Medina 2013). We can, as Pritchard (2004) argues, be epistemically lucky or unlucky. Someone born into a family, community, or culture, or hired and socialized into an organization promoting prejudicial ideas about superior views, or 'facts' and 'evidence' being inferior to opinion or gut instinct might, for instance, be considered epistemically unlucky (Battaly 2017a). In this case, such agents may carry a relatively low level of responsibility for possessing and exhibiting what appears to be epistemic vice. Anyone apportioning epistemic vice along responsibilist lines must therefore pay close attention to the epistemic obstacles agents may have faced, situationally and socially (Kamtekar 2004).

Another issue concerning the nature and structure of responsibilist epistemic vices is whether or not they should be treated as character traits in the stable, dispositional sense of the term. Some vice epistemologists follow Aristotle in arguing that vices are deep and lasting qualities of an agent that cause them to think and act in (relatively) stable ways (e.g., Zagzebski 1996). Recently, however, some vice epistemologists have argued that attitudes and ways of thinking could make up less restrictive conceptualizations of epistemic vice (Cassam 2016; Tanesini 2016). Agents might, for instance, engage in wishful thinking or ignore contrary evidence on some political and economic issues, but not others. These more inclusive views on epistemic vice may go some way toward appeasing critical voices within virtue/vice theory who have raised concerns over the idea of agents possessing something like robust, dispositional character traits at all. Drawing from work in social psychology, Harman (2000) and Doris (2002) have argued that human behavior, epistemic or otherwise, is determined not by dispositional traits but by situational factors, such as whether or not a person is in a hurry. Their situationist critique of virtue theory has generated much debate within business (virtue) ethics (e.g., Alzola 2008; Solomon 2003). Whether epistemic vices do or do not have to be character traits might, in our view, be considered as a matter of degree or disposition-situation interactivity, to be theorized and tested further in particular organizational and ethical-epistemological contexts (Johns 2017).

One final issue currently being considered within virtue and vice epistemology is whether or not epistemic virtues and vices can and should be ascribed to collectives in addition to individuals (e.g., de Bruin 2015; Fricker 2009; Lahroodi 2007). Higher-order actors in the aggregate-boards, institutions, large firms, and other collectives-could all be held to share certain epistemic habits or outlooks toward information, knowledge, and truth that concerns them (Kilduff et al. 2011). Lahroodi (2007), for instance, argues that both individual and group epistemology can co-vary, such as a church committee that is narrow-minded toward gay rights as a group, while all or most members are 
open-minded about gay rights. Similarly, group-level social cognitive biases and conformity pressures, such as groupthink and the Abilene paradox, show how groups can tend toward expressions of knowledge, decision, and behavior that are independent and divergent from the underlying or prior cognitions of individual members (e.g., Kim 2001).

Fricker (2009) also argues for attributing epistemic virtues and vices to collectives, where individuals, despite personal beliefs and traits, make a joint commitment as 'plural subjects' to the beliefs and responsibilities of a group-a political party, for example. In discussing epistemic virtues within the financial services industry, de Bruin (2015) contends that corporate epistemic virtues and vices matter. $\mathrm{He}$ sees such things as organizational functions, decision-making structures, corporate culture, and sanctioning systems as loci of corporate epistemic virtue and vice. As per multilevel management theory more broadly, some virtues and vices may emerge or aggregate from individual group member distributions, while others may be irreducibly collective (e.g., Morgeson and Hofmann 1999).

In sum, a reliabilist view of epistemic vice points to cognitive qualities that an agent arguably cannot and should not be blamed for possessing. A responsibilist view, by contrast, points to acquired motives and cognitive character traits for which an agent has some responsibility for, and for which they may merit some blame. Here we opt to confine epistemic vices to a responsibilist view for the purpose of appreciating how organizations can hold actors accountable for their expression, and make efforts to ameliorate vices that obstruct the acquisition or transmission of epistemic goods. We have also stressed the importance of exercising prudence when charging agents with epistemic vice, and that while some vice epistemologists think that epistemic vices need to be cognitive character traits, others hold that attitudes and ways of thinking should be included too. Finally, in addition to ascribing epistemic vices to individuals, we have shown how groups and institutions can and arguably should be ascribed epistemically virtuous or vicious status. We now turn to look more closely at why epistemic vices deserve greater attention by virtue epistemologists and business ethicists more generally.

\section{The Importance of Epistemic Vices in Addition to Virtues}

There are important reasons for theorizing and studying vice epistemology as distinct from virtues. In work on virtue (and vice) epistemology, until very recently, considerably more treatment has been given to the epistemic virtues than vices (Cassam 2016), meaning we know far more about epistemic virtues than we do the vices. We suggest three reasons why it is at least as important, if not more so, to focus on epistemic vice over virtue: (1) few actors are model epistemic agents;
(2) theories of epistemic virtue leave us with an incomplete view of epistemic agents; and (3) amelioration of epistemic conduct partly depends on uncovering and understanding vices.

\section{Few Actors are Model Epistemic Agents}

Epistemic vices matter because many actors do not correspond to the idealized rationality of 'homo philosophicus' (Cassam 2014) or 'homo economicus' (Thaler 2000). For most actors at work in organizations, there is a wide range of pernicious epistemic vices reflected in their conduct. Notions of actors' bounded rationality, as cognitive misers conserving limited intellectual resources, and difficulties rooting out incompetence and vested interests all reflect challenging terrain for organizations in relation to valuing truth and principled inquiry over ignorance and fluency (Alvesson and Spicer 2012).

Acknowledging epistemic vice is therefore a necessary corrective to dominant approaches that emphasize managers' and leaders' virtues (Vince and Mazen 2014). A commitment to vice is thus also a commitment to the primacy of the non-ideal. Rather than appeal to an 'idealized knower,' a vice epistemology remains attentive to the context and conduct of individuals and groups operating in suboptimal epistemic conditions (Brady and Pritchard 2003). To properly understand normative epistemic activities and offer guidance for epistemic interactions inside organizations, it seems important to avoid idealizations of knowing and to recognize the messy realities of practice (Schön 1983). This includes the prioritization of real epistemic obstacles and vices over ideal enablers and virtues. Medina (2013, p. 38) argues that "we should start our theorizing by reflecting on the details of the actual injustices [epistemic vices] that surround us, rather than by speculating about what perfect justice [epistemic virtue] might be." Indeed, assuming epistemic virtues are normal and widespread seems unlikely, over-optimistic and one-sided, given the complexity of organizations' knowledge management demands and the general operations of power, politics, and conflict.

\section{Epistemic Virtue Gives an Incomplete View of Epistemic Agents}

We also propose that epistemic virtues are insufficient for explaining the full epistemological predicament of individuals and organizations. Vices matter because "virtues would be unreal if they did not have an opposite alternative. The vices are the defects of our qualities. Our nature provides for both" (Midgley 2001, p. 3). Uncovering why some agents care little about epistemic goods is surely as important a question as why some agents do care (Kraemer 2015). In terms of the prevalence and influence of 
epistemic vices, we have little clear understanding of what epistemic vices exist, why they are so prevalent, or what functions, needs, and motives they serve-particularly inside organizations. Although certain cognitive biases are held to be a part of our psychological nature (e.g., Samuelson and Church 2015), we know little of how these biases interact with acquired epistemic traits and motivations, or how epistemic vices might compound our cognitive biases. To confront the errors individuals and organizations are prone to as inquirers, it would seem necessary and worthwhile to better understand the variety and range of epistemic conduct that might occur. A commitment to vice is thus a commitment to a more complete understanding of the epistemological context and conduct of epistemic agents.

\section{Amelioration of Conduct Depends on Uncovering and Understanding Epistemic Vices}

Finally, a one-sided focus on epistemic virtue over vice is partly explained by the presumption that vice is simply the absence of virtue (Midgley 2001). This assumption is strongly challenged, however, by the idea that epistemic vice can be positively cultivated and actively strengthened by various mechanisms (Tanesini 2016). This failure to actively recognize and theorize epistemic vices may contribute to the invisibility of everyday epistemic vice inside organizations and the formation of reinforcing patterns of ignorance that perpetuate it and desensitize us to its harmful effects (Medina 2013). As we argue further below, various forms and degrees of epistemic vice are often unfolding inside organizations, where agents show little to no regard for evidence, try to oppose epistemic goods that do not serve their vested interests, devalue minorities as potential knowers, and exaggerate their epistemic capabilities, often with devastating consequences. To ameliorate perceived deficiencies in epistemic agents in such cases, it makes sense to identify and study epistemic vices and mechanisms that compound, constrain, or remedy them in organizations (de Bruin 2015). A commitment to vice is thus a commitment to understanding and ameliorating the conduct of contemporary epistemic agents, as well as fostering more corporate epistemic virtue in the form of knowledge sharing, democracy, and learning.

Taken together, these three inter-related justifications go a long way, we believe, toward verifying that there is both space and need for a vice epistemology, particularly one sensitive to the context of business and organization. Or, as Kidd (2015, p. 1) argues: "Vice epistemology is not an abstract exercise for the armchair, but a real contribution to the understanding and amelioration of our social world."

\section{Epistemic Vices in Organizations: Four Illustrative Examples}

Thus far we have discussed the purview of vice epistemology, the nature of epistemic vices, and the seriousness of studying them in relation to societies and organizations. Below we select and focus on four types of epistemic vicemalevolence, insouciance, hubris, and injustice. These are intended as illustrative examples rather than being exhaustive of all possible epistemic vices, but we argue that they are likely to be prevalent in many organizations, and that they reflect significant opposing forces to many major epistemic virtues (de Bruin 2013). They should be considered inter-related rather than mutually exclusive, as overlapping, co-occurring, and reflecting varying degrees of vicious agency and intent, individual and/or collective. We follow de Bruin (2015) and others (e.g., Lahroodi 2007; Fricker 2009) in asserting that epistemically virtuous/vicious behavior can be ascribed to collectives in addition to individuals. As our examples reveal, different organizational aims, structures, and cultures can intentionally or unintentionally obstruct the effective and responsible acquisition or transmission of epistemic goods, even if no single actor within the organization may be said to be epistemically vicious. Finally, our examples are presented as offering a window onto the wider possibilities of borrowing and blending concepts from the vice epistemology field, and using them to build valuable organization theory (Oswick et al. 2011). For treatment of epistemic vices outside of the four discussed below, additional examples might include epistemic insensibility (Battaly 2013), self-indulgence (Battaly 2010), conformity (Battaly 2014), close-mindedness (Battaly 2017b), and dogmatism (Rokeach 1960).

\section{Epistemic Malevolence}

Epistemic malevolence is willful, active, and deep opposition to the epistemic good. Baehr (2011) argues that epistemic malevolence may be either personal or impersonal. Personal where the epistemically malevolent agent (roughly) opposes another person's or group's share in knowledge or their epistemic well-being. A dictator who takes active measures to thwart their citizens' access to knowledge/epistemic goods is one typical example. In contrast, impersonal malevolence is where the epistemically malevolent agent (roughly) opposes epistemic goods in general. This could be a demonic and destructive agent who systematically deceives, appearing to delight in misleading all who desire to acquire epistemic goods, being strongly opposed to a clear idea of something like truth and knowledge public good. Baehr (2011) therefore contends that epistemic malevolence amounts to one of the strongest, purest, most wicked forms of epistemic vice. If epistemic virtue is fundamentally a 
matter of being in favor of the acquisition and transmission of epistemic goods, staunch general opposition to these goods would epitomize epistemic vice and malevolence.

Perhaps unfortunately from a virtue epistemology perspective, management and organization is arguably replete with examples of epistemically malevolent agents-those who actively work to corrupt epistemic cultures and prevent the acquisition of epistemic goods. These malevolent agents are conceptualized by Kidd (2016) as 'agnotogenic agencies' - individuals, groups, and organizations dedicated to the spread of ignorance and confusion (Gross and McGoey 2015; Roberts and Armitage 2008). Pacepa and Rychlak (2013) provide a detailed account of epistemically malevolent organization when they reveal the history and tactics of Russian-led 'dezinformatsiya' campaigns. These campaigns sought to systematically and intentionally deceive public opinion using false information. Their success, as judged by their architects, rested on whether the mainstream media was sufficiently duped into publicizing deliberate falsehoods, and whether the consumers of such media believed the accounts accurate. Operation INFEKTION, for example, was revealed to be a Soviet deception campaign that sought to influence public opinion that the U.S. invented HIV/AIDS. Even the word 'dezinformatsiya' was given a French-sounding title to deceive others into believing it had originated in the west (Pacepa and Rychlak 2013).

Allegations continue to be made that many agencies, government and otherwise, systematically spread misinformation in attempts to profit from it. Facebook and other social media platforms have been harshly criticized for their creation of monetary incentives to spread falsehoods. Generators of fake content can solicit payment for their services and then subsequently pay Facebook to promote fake stories (Ohlheiser 2016). In early signs that such platforms are considered by other firms as illegitimate and epistemically malevolent, Unilever has recently threatened to pull its advertising from those platforms contributing to the spread of fake news and its ilk (Russon 2018). The managerial consequences of firms engaging in or facilitating such epistemically malevolent behavior will be a fruitful area for future research. Here, as with our earlier example of 'dezinformatsiya' campaigns, we find a case where an entire organization may be said to be behaving in epistemically vicious ways. For Operation INFEKTION, it is their organizational aim that is epistemically malevolent. For Facebook, it is their platform's incentivization of such behavior that is so.

If organizations do not find internal agents willing to actively oppose the epistemic well-being of stakeholders, there are evidently plenty of other malevolent brokers of deception and misinformation for sale. Oreskes and Conway (2012), for example, show how dozens of high-level scientists and spin doctors ran effective campaigns to intentionally mislead and cloud the public's understanding of the dangers of tobacco smoke, acid rain, asbestos, and global warming. "Doubt is our product," declared one such tobacco company executive (Oreskes and Conway 2012, p. 34). Recognizing that the industry could not simply deny the overwhelming scientific consensus on the hazards of tobacco smoke, it paid 'merchants of doubt' to use otherwise normal scientific uncertainty to undermine the status of genuine scientific knowledge and manufacture the impression that findings were inconclusive. Thousands of internal tobacco company documents released through whistleblowers and litigation revealed, however, the industry executives' acute awareness of their systematic deceit (Oreskes and Conway 2012). In regulation-heavy industries in general, large organizations may feel strategically empowered to deliberately manipulate unfavorable information by stalling for time, lobbying, and manipulating the terms of debate (Marcus 1987). In public relations, 'astroturf' campaigns are designed to elaborately fake the appearance of grassroots support for organizations that want to appear on the right side of an epistemic issue (Glaser 2012).

Such epistemic wickedness and malevolence may be difficult for moral philosophy to fully isolate and understand in terms of motives and responsibility (Midgley 2001). Anywhere, however, in the politics of a knowledge economy where organizations and individuals are implicated in potential lobbying, propaganda, secrecy, misinformation, espionage, and other deceitful campaigns, we might expect to find this vice in practice.

\section{Epistemic Insouciance}

To be insouciant is to be indifferent. To be epistemically insouciant is to be indifferent or show a casual lack of concern toward epistemic goods (Cassam 2018). Following Roberts and Wood (2003), we have stated that epistemic goods include such properties as 'truthfulness,' 'justification,' 'coherence,' 'knowledge,' and 'reasoning.' Showing a lack of concern toward these goods undermines their wider acquisition and transmission. Epistemic insouciance is thus an epistemic vice in that it gets in the way of the effective and responsible acquisition and transmission of epistemic goods.

As with our other example vices, there are numerous cases to draw upon where we might find this vice in practice. Many debates on social media platforms around political events in the UK and US have, for instance, involved voters and politicians alike enacting a culture of epistemic insouciance by questioning the value of evidence and statistics being quoted at them, and instead preferring to stick to their own views (e.g., Hinsliff 2016). Such actors do not appear to be concerned with genuinely critiquing forms of evidence and analysis, but rather with dismissing epistemic goods and uncritically maintaining their beliefs. This kind of 
epistemic insouciance begets wishful thinking and is fueled by confirmation biases. When people act based on this kind of epistemic conduct at the voting booth, the consequences of their doing so may lead to disturbing outcomes. This is especially true when the agent in question is epistemically insouciant toward far-reaching and materially consequential epistemic issues - for example, understanding the pros and cons of the UK's relationship with the European Union. It is arguably less important if the matter to which one is epistemically insouciant is of lower significance-for example, cultivating knowledge about the color changes of a celebrity's hair (Battaly 2013).

In characterizations of a twenty-first century 'post-truth' information era, epistemic insouciance has-under various guises-received significant attention within scholarly and popular discourse (Davis 2017; D'Ancona 2017). Management and organization have been strongly implicated in its systematic production (Alvesson and Spicer 2012; Spicer 2017). Explicitly or implicitly, many organizations encourage or condone a lack of reflexivity, investigation, substantive reasoning, and justification among members (e.g., Alvesson and Spicer 2012; Jackall 1988). Naomi Klein (2000), for example, describes the epistemically insouciant advertising agency director who advises their marketing team never to visit the factories from which the products they promote came, knowing this truth would make the superficial adverts they write much more difficult and less effective. Ten Bos (2007) cites Whyte's (1956) study of an epistemically insouciant American oil company culture which thwarted its workers' pursuit of epistemic goods through the following unequivocal advertisement: 'No Virtuosos Here!'

Organizations are also implicated in the creation, circulation, and consumption of substantial quantities of talk and text which have little respect for or relationship to evidence or justification. Building on the seminal work of Harry Frankfurt (2005), Spicer (2013) explicitly labels this kind of organizational discourse 'bullshit,' with modern management offering a "veritable treasure trove of examples" (p. 658). Barriers to learning and rationality can appear legion, and the willful blindness, individual and collective, to deeper consideration of important ethical issues can seem troubling and alarming (e.g., Bazerman and Tenbrunsel 2011; Palazzo et al. 2012).

While many of these works provide accounts of why individuals and organizations might actively support epistemic insouciance, they are largely absent of engagement with the ethical and epistemological implications of doing so, tending to use more descriptive or value-neutral terms, describing outcomes of systems with a mixture of functionally dysfunctional properties. This leaves open considerable space for business ethicists to inquire about the ethical implications of fostering managerial dispositions that disregard evidence or justification-that is, supporting the production of epistemic insouciance. Individuals, organizations, and interest groups that either have, or encourage others to have, scant regard for evidence and epistemic goods ought perhaps to be challenged as to how evidence-based their principles and decisions are, if they are unreasonably rejecting opportunities for reflection and dialogue (Erez and Grant 2014). Some, but not all, of the worst corporate, natural, and humanitarian disasters might have been prevented had only evidence been valued, reflexivity encouraged, justification required, and knowledge sought, both individually and collectively (Nam and Lemak 2007).

\section{Epistemic Hubris}

Epistemic hubris is an inflated sense of epistemic privilege and pride (Ogden 2017). Bound closely to power, arrogance, and over-confidence, it manifests in one of two ways, but the epistemically hubristic may often exhibit both in relation to their knowledge, credibility, and expertise.

The first is the conviction that one has epistemic authority or superiority where one in fact lacks it (Kraemer 2015). It thus involves a false inference about the state of one's knowledge and expertise relative to others (Roberts and Wood 2007). Consider, for instance, the hubristic property tycoon who claims they need no prior training or knowledge of political theory in order to master the governance of a country. They believe their status in business makes them best-placed to judge the relative merits and demerits of foreign and domestic policy, when this is surely false. In contrast, epistemic authority can be said to more legitimately rest on a person's knowledge and understanding of the issues at stake, not on their positional status (de Bruin 2013). In the worst cases then, those agents who possess this first kind of epistemic hubris indulge in a kind of delusional cognitive omnipotence (Spengler 1972). They over-exaggerate their knowledge claims and frequently misjudge the realities of the situation (Claxton et al. 2013). Importantly, we would add that it is not simply an error of judgment which qualifies epistemic hubris as an epistemic vice. It is of course possible to misjudge a situation or to be incorrect without being hubristic. It is the agent's conviction of their infallibility and epistemic superiority that is constitutive of this vice.

A second, subtler manifestation of epistemic hubris is the conviction that one has the right or privilege not to know, or not to need to know (Tanesini 2016). Machineries of oppression can serve to render violent events such as genocide invisible within hubristic cultures (Medina 2013), hidden from the privileged classes' sight to protect and spare them from any unnecessary 'trouble' that might accompany 'knowing' (Stokes and Gabriel 2010). More commonly, the privilege to ignore many ethically significant facts of social and organizational life is frequently exercised by those 
wielding power within workplaces (Jackall 1988). When managers or executives ridicule the considerations of the corporate social responsibility (CSR) department as being trivial or none of their concern, for example, this instantiates this second kind of epistemic hubris. This kind of epistemic hubris also manifests when agents attempt to inoculate themselves against dissenting voices (Stein 2003), or when they hold contempt toward the advice and/or criticism of others (Owen and Davidson 2009). Feelings of power can reduce empathy, compassion, and attentiveness to others (Van Kleef et al. 2008), and leader-follower dynamics and distances may reinforce a leader's privileges to not know or care about matters deemed trivial or beneath them (e.g., Gabriel 1997). Thus, not only do the epistemically hubristic make deliberately false inferences about the limits of their knowledge, they may also infer that some areas of (important) social inquiry or knowledge acquisition are not worth being known, or simply beneath their consideration.

As with the other vices, epistemic hubris undermines a growth in epistemic goods, given that "When whatever one says, goes-because one's word is the law or the truth others are bound to uphold and abide by-there is a complete lack of resistance from the world and from others that gets in the way of knowledge acquisition" (Medina 2013, p. 33). Epistemic hubris may unknowingly and relationally promote other epistemic vices in those party to it, in their servility and timidity. Depending on whether they are led by hubristic or humble leaders, for instance, teams show decreased and increased acquisition of knowledge, respectively (Nevicka et al. 2011; Weiss and Knight 1980). If followers feel psychologically safe to speak up about errors and learning across organizations, then epistemic hubris might be reduced or less likely to emerge (Detert and Burris 2007).

Recently, hubris as a subject of management inquiry has achieved considerable attention, including several reviews (e.g., Picone et al. 2014; Sadler-Smith et al. 2017). Theories on hubris have been developed to explain a range of organizational phenomena, including venture failure (Hayward 2007), reckless risk-taking (Haynes et al. 2015), leader under-performance (Malmendier and Tate 2009), and poor acquisition valuations (Roll 1986). It is generally considered to be dysfunctional, if not ethically vicious. Unlike here, however, these studies do not separate epistemic hubris from hubris more generally. We locate the difference in epistemic hubris in terms of how it uniquely relates to the arrogance and over-confidence surrounding knowing.

\section{Epistemic Injustice}

In addition to other economic, political, and social types of injustice in organizations, epistemic injustice describes someone being specifically wronged in terms of their credibility and capacity as a knower (Fricker 2003, 2007).
Epistemic injustice has roots in social epistemology and feminist theory, given that often women and other social minorities can be mistreated in terms of judgments of their credibility. Given the relatively large stream of work on types of organizational justice (e.g., Rupp et al. 2017), it is surprising that epistemic (in)justice has not, to our knowledge, been considered in much detail within management and organization theory (although see de Bruin 2015, for some initial application to financial services). In her pivotal book-length treatment of the subject, Epistemic Injustice: Power and the Ethics of Knowing, Miranda Fricker (2007) defines and distinguishes two main forms of epistemic injustice: (1) testimonial, where a deflated level of credibility is attributed to someone's communications because of their social status; and (2) hermeneutic, where someone lacks the social resources to articulate and make sense of their own experiences, and may not even believe themselves to know anything. The two need not be mutually exclusive, necessarily - a 'double' victim of this sort of injustice could both have their testimonials not believed by powerful others while also doubting their own minds in representing a reality credibly and capably to themselves and other victims.

As with the three vices above, critical examples of this conduct in organizations and business abound. Anywhere in organizations and societies where there are gendered, ethnic, disabled, or other minorities, there is a likelihood of many epistemic injustices of both forms occurring (Kidd et al. 2017). An employee with a healthcare or disability issue may either not be believed by epistemically unjust managers or doctors (testimonial), or find it difficult to explain, formulate, and secure reasonable adjustments (hermeneutic) (Kidd and Carel 2017). Women may report having their workplace testimonials or contributions ignored or 'mansplained' back to them in an epistemically unjust culture, where men are unfairly discrediting, then re-appropriating, their role as a credible knower (Luzzi 2016). In Obama's White House Oval Office, for example, women used a strategy of 'amplification' to collectively combat epistemic injustice and boost their credibility, by overtly recognizing and repeating one another's verbal contributions to strategy and policy discussions (Eilperin 2016).

Anywhere employees, subordinates, or middle managers are not believed or taken seriously as credible epistemic agents in organizations, they may have to work harder at 'issue selling' - using bottom-up influence tactics to achieve organizational change and make a credible case to decisionmakers and stakeholders with greater influence (Dutton et al. 2001). Epistemic injustice is still an emerging notion in epistemology, but it seems likely that in organizations, downplayed or discarded testimonies and hermeneutic struggles to feel credible to oneself and others pose a serious issue for fostering open and inclusive cultures. Perceptions of epistemic fairness and unfairness may vary over time and 
across different parties, and require coordinated institutional efforts to track their cumulative and systemic effects (Anderson 2012).

Left unchecked, there is the risk that groups continue to be silenced and marginalized, and epistemic injustice morphs and extends into epistemic oppression, a persistent exclusion from knowledge production (Dotson 2014). Expressed more manipulatively and deceptively, epistemic injustice may come to resemble epistemic malevolence as described above. Gaslighting, for example, concerns epistemically unjust actors unjustly manipulating others' realities to cause them to doubt themselves and feel as if they are losing their minds, to find all their testimony discredited and themselves lacking the resources to interpret the very grounds of their reality (Abramson 2014; McKinnon 2016).

Recently, Battaly (2017a) has raised some doubts over the status of epistemic injustice as a responsibilist epistemic vice. Recall from our earlier discussion that in order for epistemic injustice to qualify as a responsibilist epistemic vice, the agent in question must have some control over their possession of it. Battaly (2017a) uses a number of interesting, albeit extreme, examples to argue that those who remain inside highly insular organizations (for example, the Taliban or ISIS) may not qualify for epistemic injustice in the responsibilist tradition. They simply are not afforded the opportunity to know better, and lacking control over their epistemic circumstances cannot be blamed for their prejudices. However, in her recent work, Fricker (2016) has argued that we can still be blameworthy for epistemically vicious behavior that is "beyond our ken and control" (p. 41), where "uncharacteristic acts and motives can still be ours in the relevant sense-features of our epistemic system" (p. 41). This raises a number of interesting challenges for vice epistemologists, such as how to distinguish between "dispositions that have their source in the agent's epistemic character or system from dispositions that "merely flow through" the agent but have their source in the environment" (Battaly 2017a, p. 230). As business ethicists have long argued, unethical behavior is rarely a simple case of 'bad apples' doing bad things. We need to be willing to look for bad barrels (organizations) and even bad orchards (institutions) (Ashkanasy et al. 2006; Trevino and; Youngblood 1990).

\section{Managing Epistemic Vices in Organizations: An Agenda for Research and Practice}

In this article, we have argued for the general importance of drawing on virtue epistemology to better understand the epistemic conduct of organizations and actors in organizational systems, in terms of contexts where claims to truth and knowledge are continually being expressed, renegotiated, and acted upon by epistemic agents. We have argued that while epistemic virtues have received some recent attention in business ethics and virtue epistemology, epistemic vices have remained more neglected. Accordingly, we have made a case for the importance of vice epistemology in organizations, providing some illustrative examples of conceptualizations of vices and where they can occur in various organizational contexts. We conclude this article with some more specific opportunities and contributions constituting an agenda for theoretical, research-driven, and practical engagement with epistemic vices (and often, by implication, virtues also) in organizations.

First, as with any social or normative construct, there is a level of analysis question around how best to attribute vicious epistemic conduct to individuals, groups, and institutions at different levels of social aggregation. We have outlined some arguments about whether groups and institutions can and should be ascribed a status as genuine cognizers that are either vicious or virtuous (Fricker 2009; Lahroodi 2007). However, work in this area is still very nascent, and how virtue and vice epistemology emerge across different levels of analysis merits further consideration, as we indicate below in terms of related issues of agency, responsibility, and culture.

There is also the issue of the desirability and feasibility of tackling epistemic vices; whether organizations can or should care about affecting the acquisition and transmission of epistemic goods, and on what basis. de Bruin (2013) develops an instrumental view of epistemic virtue as enabling and motivating people inside organizations to perform epistemic actions. In terms of learning, knowledge, deeper forms of inquiry, and building accurate and innovative forms of consensus, by acquiring epistemic goods organizations better align their actions with reality and thus improve their prospects of achieving success and creating value more widely (Wei Choo 2016). In fact, much virtue epistemology primarily considers the promotion of virtue and reduction of vice as intrinsically valuable (Baehr 2011). Nevertheless, an instrumental approach helps to explain which epistemic goods a person should aim to achieve, why, and under what stakes, incentives, or conditions.

Bad epistemic outcomes such as ignorance, denial, and fabrication are likely to be cultivated to serve business ends, at least in some cases (Alvesson and Spicer 2012; Oreskes and Conway 2012). Epistemic vices might therefore be functional and instrumental to the success of some organizations, but this does not excuse those who perpetuate them from the moral implications of doing so. As with diversity management or CSR, there will often be a 'business case' and a 'moral case' to pursuing various prosocial practices, cultures, and behaviors, the latter going beyond a narrow instrumental orientation. From an evolutionary perspective, as social organisms hoping to trust one another and cooperate, it is generally important for us to communicate clearly 
and honestly most of the time, and to stay alert and deter and punish those who distort information by vicious epistemic conduct (Sperber et al. 2010), albeit with the important qualification that deceit and self-deception confer advantages too (Trivers 2011).

On this point, Kidd (2016) has discussed the idea that actors can challenge epistemic vices through the critical practice of 'epistemic vice charging,' which is essentially the act of 'calling out' others for their epistemic misconduct. Kidd (2016) does note, however, the considerable difficulties in practice of assuming responsibility for epistemic issues, as well as building consensus in convincing the target and others, which may require further epistemic divisions of labor. Echoing concerns regarding the difficulties of tackling epistemic vice and promoting epistemic virtue, Borg and Hooker (2017) express skepticism that organizations or regulatory bodies can do much to ameliorate (unethical) conduct by directly focusing on them. Epistemic motivations and conflicts in organizations, moral and instrumental, thus merit future research along these lines, as do the limitations of epistemic virtue theory as applied to business contexts and cultures. In the case of banking, for instance, Herzog (2017) has argued that professional associations and regulators need to work together to align banking communities around preventing epistemic harms to clients and societies, as well as promoting epistemic virtues and goods.

A deeper, critical problem concerns how epistemic vices can often be cloaked or disguised as their opposite, where the very presence or declaration of epistemic virtue is in fact more indicative of vice. Authenticity becomes fakery, sincerity becomes dishonesty, humility becomes self-aggrandizement, skepticism becomes gullibility, and so on-until virtues and vices become blurred and oxymoronic. Glaser (2012) has made this argument quite forcefully in terms of highlighting the use of covert ideologies and soft power techniques to disrupt the relationships between appearances and realities, where saying, meaning, and doing have become decoupled. Research on epistemic vices should therefore remain explicitly concerned with false virtues hiding in plain sight, considering inconsistencies between the sayings, meanings, and doings of organizational actors. This might include considering levels of epistemic vigilance to soft or covert power techniques, ironic discrepancies between intentions and outcomes, and the perceived hypocrisy of inconsistent talk, decisions, ideas, and actions.

For the sake of epistemological reflexivity, reflections on more extreme postmodern perspectives on epistemic vice also merit further development. Long have postmodern thinkers such as Jean-Francois Lyotard and Jean Baudrillard put forward radical epistemological views, whether it is skepticism toward 'grand narratives,' or seeing the epistemological state of play in organizations as metaphorically akin to a house of mirrors, Russian Doll, theatrical performance or computer simulation in terms of the fragmented and layered claims to truth and reality (e.g., Boje 1995; Gustafson 2000). It would be interesting therefore to consider the implications of these perspectives in terms of epistemic vices and virtues. For instance, whether or not it is possible to fight epistemic vice without being complicit in it, whether epistemic agency should concern itself with 'small narratives' only, or how to balance a playful and rebellious attitude with a responsible one toward epistemic conduct, and so on. Beyond postmodernism, the same holds for other critical management epistemologies, such as feminism and psychoanalysis (Adler et al. 2007).

A key contextual recognition for future research on epistemic vices lies in terms of the digital and media environment of organizational communications. Aspects of the Internet, big data, and social media may exacerbate certain forms of epistemic vice, leading to novel forms of epistemological chaos or crisis (e.g., Nunan and Di Domenico 2017). Dennett and Roy (2015), for example, have argued that the radical transparency of the Internet and related developments will create evolutionary pressures on organizational forms to evolve newly sophisticated ways of detecting and obfuscating knowledge and credibility. 'Filter bubbles' and 'echo chambers' that only provide us with information and responses filtered to confirm our subjective biases will be erected and circumnavigated through different forms of epistemic conduct in relation to organizations (Bozdag and van den Hoven 2015; Vaccari 2013).

Finally, virtue and vice epistemology can be directed toward diverse and changing epistemic communities, values, and (un)ethical practices. Aristotle's epistemological concepts of techne, poiesis, phronesis, praxis, sophia, and episteme, for example, all denote inter-related scientific, practical, and moral ways of knowing (Chishtie 2012). Increasingly, more diverse ways of knowing rooted more directly in practice, craft, judgement, the body and collectivities are being recognized in management (e.g., Gärtner 2013; Rennstam and Ashcraft 2014). Furthermore, Cook and Brown (1999) propose that effective knowledge management and innovation in organizations rests on the ability to bridge epistemologies or ways of knowing, moving between individual and group knowing, and tacit and explicit knowing, to arrive periodically at newly valuable forms of knowledge and knowing in the process. Similarly, we propose that epistemological vices and virtues are likely to be enacted through the interactions, intersections, and movements between different ways of knowing and the knowledge they produce.

\section{Conclusion}

Combining aspects of virtue ethics and epistemology, virtue epistemology pursues a program seeking to overcome the longstanding preoccupation of epistemology with skepticism 
and with arcane efforts to define knowledge, and to reestablish epistemology as a discipline with a broader social and organizational importance (Roberts and Wood 2007). By shifting emphasis from analytical properties of beliefs to the epistemic characteristics of agents, virtue epistemologists open up a new epistemological program suggesting that we can and should promote epistemic well-being, humanize and deepen epistemology, ameliorate epistemic characters and communities, and provide a more complete account of concepts such as 'knowledge,' 'evidence,' and 'justification' beyond a purely non-normative vocabulary (Zagzebski 1996). In this paper, we have focused on epistemic vices and vice epistemology in particular, as neglected but important in their interdependent relations with epistemic virtues. We hope that the epistemic vice agenda laid out here will give scholars and practitioners novel ways of reevaluating the business ethics of truth, knowledge, and knowing.

Funding No funding has been received for the conduct of this study and/or preparation of this manuscript.

\section{Compliance with Ethical Standards}

Conflict of interest Christopher Baird and Thomas S Calvard declare that they have no conflict of interest.

Ethical Approval This article does not contain any studies with human participants or animals performed by any of the authors.

Open Access This article is distributed under the terms of the Creative Commons Attribution 4.0 International License (http://creativeco mmons.org/licenses/by/4.0/), which permits unrestricted use, distribution, and reproduction in any medium, provided you give appropriate credit to the original author(s) and the source, provide a link to the Creative Commons license, and indicate if changes were made.

\section{References}

Abramson, K. (2014). Turning up the lights on gaslighting. Philosophical Perspectives, 28(1), 1-30.

Adler, P. S., Forbes, L. C., \& Willmott, H. (2007). Critical management studies. The Academy of Management Annals, 1(1), 119-179.

Alvesson, M., \& Spicer, A. (2012). A stupidity-based theory of organizations. Journal of Management Studies, 49(7), 1194-1220.

Alzola, M. (2008). Character and environment: The status of virtues in organizations. Journal of Business Ethics, 78(3), 343-357.

Anderson, E. (2012). Epistemic justice as a virtue of social institutions. Social Epistemology, 26(2), 163-173.

Annas, J. (2003). The structure of virtue. In L. Zagsebski \& M. DePaul (Eds.), Intellectual virtue: Perspectives from ethics and epistemology (pp. 15-35). New York: Oxford University Press.

Argyris, C. (2003). A life full of learning. Organization Studies, 24(7), $1178-1192$.

Arjoon, S. (2000). Virtue theory as a dynamic theory of business. Journal of Business Ethics, 28(2), 159-178.

Ashkanasy, N. M., Windsor, C. A., \& Treviño, L. K. (2006). Bad apples in bad barrels revisited: Cognitive moral development, just world beliefs, rewards, and ethical decision-making. Business Ethics Quarterly, 16, 449-473.

Baehr, J. (2010). Epistemic malevolence. Metaphilosophy, 41(1-2), 189-213.

Baehr, J. (2011). The inquiring mind: On intellectual virtues and virtue epistemology. Oxford: Oxford University Press.

Ball, J. (2017). Post-truth: How bullshit conquered the world. London: Biteback Publishing.

Battaly, H. (2010). Epistemic self-indulgence. Metaphilosophy, 41(12), 214-234.

Battaly, H. (2013). Detecting epistemic vice in higher education policy: epistemic insensibility in the seven solutions and the REF. Journal of Philosophy of Education, 47(2), 263-280.

Battaly, H. (2014). Varieties of epistemic vice. In J. Matheson \& R. Vitz (Eds.), The ethics of belief (pp. 51-76). Oxford: Oxford University Press.

Battaly, H. (2016). Responsibilist virtues in reliabilist classrooms. In J. Baehr (ed.) Intellectual virtues and education: Essays in applied virtue epistemology (pp. 163-187). London: Routledge.

Battaly, H. (2017a). Testimonial injustice, epistemic vice, and vice epistemology. In I. J. Kidd, J. Medina \& J. G. Pohlhaus (Eds.), The Routledge handbook of epistemic injustice (pp. 223-231). Milton Keynes: Taylor and Francis.

Battaly, H. (2017b). Closed-mindedness and intellectual vice. Keynote Address, Harms and Wrongs in epistemic practice conference, University of Sheffield, 4 July.

Bazerman, M. H., \& Tenbrunsel, A. E. (2011). Ethical breakdowns. Harvard Business Review, 89(4), 58-65.

Boje, D. M. (1995). Stories of the storytelling organization: A postmodern analysis of Disney as "Tamara-Land". Academy of Management Journal, 38(4), 997-1035.

Borg, E., \& Hooker, B. (2017). Epistemic virtues versus ethical values in the financial services. Journal of Business Ethics (online).

Bozdag, E., \& van den Hoven, J. (2015). Breaking the filter bubble: Democracy and design. Ethics and Information Technology, 17(4), 249-265.

Brady, M. S., \& Pritchard, D. (2003). Moral and epistemic virtues. Metaphilosophy, 34(1-2), 1-11.

Buchanan, A. (2009). Philosophy and public policy: A role for social moral epistemology. Journal of Applied Philosophy, 26(3), 276-290.

Cassam, Q. (2014). Self-knowledge for humans. Oxford: Oxford University Press.

Cassam, Q. (2016). Vice epistemology. The Monist, 99(2), 159-180.

Cassam, Q. (2018). Epistemic insouciance. Journal of Philosophical Research (in press).

Chishtie, F. (2012). Phronesis and the practice of science. In E. A. Kinsella \& A. Pitman (Eds.), Phronesis as professional knowledge: Practical wisdom in the professions (pp. 101-114). Boston: Sense Publishers.

Claxton, G., Owen, D., \& Sadler-Smith, E. (2013). Hubris in leadership: A peril of unbridled intuition? Leadership, 11(1), 57-78.

Code, L. (1987). Epistemic responsibility. Hanover: Brown University Press.

Cook, S. D., \& Brown, J. S. (1999). Bridging epistemologies: The generative dance between organizational knowledge and organizational knowing. Organization Science, 10(4), 381-400.

Crossman, J., \& Doshi, V. (2015). When not knowing is a virtue: A business ethics perspective. Journal of Business Ethics, 131(1), $1-8$.

D'Ancona, M. (2017). Post-truth: The new war on truth and how to fight back. London: Ebury Press.

Davis, E. (2017). Post-truth: Why we have reached peak bullshit and what we can do about it. Boston: Little, Brown Book Group.

de Bruin, B. (2013). Epistemic virtues in business. Journal of Business Ethics, 113(4), 583-595. 
de Bruin, B. (2014). Ethics management in banking and finance. In N. Morris \& D. Vines (Eds.), Capital failure: Rebuilding trust in financial services (pp. 255-276). Oxford: Oxford University Press.

de Bruin, B. (2015). Ethics and the global financial crisis: Why incompetence is worse than greed. Cambridge: Cambridge University Press.

de Paul, M., \& Zagzebski, L. (2003). Intellectual virtue: Perspectives from ethics and epistemology. Oxford: Oxford University Press.

Dennett, D. C., \& Roy, D. (2015). Our transparent future. Scientific American, 312(3), 64-69.

Detert, J. R., \& Burris, E. R. (2007). Leadership behavior and employee voice: Is the door really open? Academy of Management Journal, 50(4), 869-884.

Doris, J. M. (2002). Lack of character: Personality and moral behavior. New York: Cambridge University Press.

Dotson, K. (2014). Conceptualizing epistemic oppression. Social Epistemology, 28(2), 115-138.

Dutton, J. E., Ashford, S. J., O’Neill, R. M., \& Lawrence, K. A. (2001). Moves that matter: Issue selling and organizational change. Academy of Management Journal, 44(4), 716-736.

Eilperin, J. (2016). How a White House women's office strategy went viral. Washington Post. https://www.washingtonpost.com/news/ powerpost/wp/2016/10/25/how-a-white-house-womens-offic e-strategy-went-viral/?utm_term=.ea54d8b2603d.

Erez, A., \& Grant, A. M. (2014). Separating data from intuition: Bringing evidence into the management classroom. Academy of Management Learning \& Education, 13(1), 104-119.

Frankfurt, H. (2005). On Bullshit. Princeton: Princeton University Press.

Freeman, E. F. (2015). Forward. In B. de Bruin, Ethics and the global financial crisis: Why incompetence is worse than greed (pp. $\mathrm{xi}-$ xii). Cambridge: Cambridge University Press.

Fricker, M. (2003). Epistemic justice and a role for virtue in the politics of knowing. Metaphilosophy, 34(1-2), 154-173.

Fricker, M. (2007). Epistemic injustice: Power and the ethics of knowing. Oxford: Oxford University Press.

Fricker, M. (2009). Can there be institutional virtues? In T. Gendler \& J. Hawthorne (Eds.), Oxford readings in epistemology (Vol. 3, pp. 235-252). Oxford: Oxford University Press.

Fricker, M. (2016). Fault and no-fault responsibility for implicit prejudice. In M. Brady \& M. Fricker (Eds.), The epistemic life of groups (pp. 33-50). Oxford: Oxford University Press.

Gabriel, Y. (1997). Meeting god: When organizational members come face to face with the supreme leader. Human Relations, 50(4), $315-342$.

Gärtner, C. (2013). Cognition, knowing and learning in the flesh: Six views on embodied knowing in organization studies. Scandinavian Journal of Management, 29(4), 338-352.

Glaser, E. (2012). Get real: How to tell it like it is in a world of illusions. London: Fourth Estate.

Greco, J. (1999). Agent reliabilism. Noûs, 33(s13), 273-296.

Griffin, M. A. (2011). Motivating reflective citizens: Deliberative democracy and the internal deliberative virtues. Journal of Value Inquiry, 45(2), 175-186.

Gross, M., \& McGoey, L. (2015). Routledge handbook of ignorance studies. London: Routledge.

Gustafson, A. (2000). Making sense of postmodern business ethics. Business Ethics Quarterly, 10(3), 645-658.

Harman, G. (2000). The nonexistence of character traits. Proceedings of the Aristotelian Society, 100, 223-226.

Haynes, K., Hitt, M., \& Campbell, J. (2015). The dark side of leadership: Towards a mid-range theory of hubris and greed in entrepreneurial contexts. Journal of Management Studies, 52(4), 479-505.

Hayward, M. L. A. (2007). Ego check: Why executive hubris is wrecking companies and careers and how to avoid the trap. Wokingham: Kaplan Publishing.
Herzog, L. (2017). Professional ethics in banking and the logic of "Integrated Situations": Aligning responsibilities, recognition, and incentives. Journal of Business Ethics. https://doi.org/10.1007/ s10551-017-3562-y.

Hinsliff, G. (2016). Trash talk: How Twitter is shaping the new politics. The Guardian (online). https://www.theguardian.com/technology /2016/jul/31/trash-talk-how-twitter-is-shaping-the-new-politics.

Hookway, C. (2003). How to be a virtue epistemologist. In M. DePaul \& L. Zagzebski (Eds.), Intellectual virtue: Perspectives from ethics and epistemology (pp. 183-202). Oxford: Clarendon Press.

Jackall, R. (1988). Moral mazes. Oxford: Oxford University Press.

Johns, G. (2017). Advances in the treatment of context in organizational research. Annual Review of Organizational Psychology and Organizational Behavior, 5(1) (in press).

Kamtekar, R. (2004). Situationism and virtue ethics on the content of our character. Ethics, 114(3), 458-491.

Kidd, I., \& Carel, H. (2017). Epistemic injustice and illness. Journal of Applied Philosophy, 34(2), 172-190.

Kidd, I. J. (2015). Report on the epistemic vices conference. https:// www.academia.edu/15719043/Epistemic_Vices_-_Conference Report.

Kidd, I. J. (2016). Charging others with epistemic vice. The Monist, 99(2), 181-197.

Kidd, I. J. (2017). Capital epistemic vices. Social Epistemology Review and Reply Collective, 6(8), 11-16.

Kidd, I. J., Medina, J., \& Pohlhaus, J. G. (2017 (eds). The Routledge handbook of epistemic injustice. Milton Keynes: Taylor and Francis.

Kilduff, M., Mehra, A., \& Dunn, M. B. (2011). From blue sky research to problem solving: A philosophy of science theory of new knowledge production. Academy of Management Review, 36(2), 297-317.

Kim, Y. (2001). A comparative study of the "Abilene Paradox" and" Groupthink". Public Administration Quarterly, 25(2), 168-189.

Klein, N. (2000). No logo. New York: Knopf.

Kraemer, E. (2015). Virtue epistemologies and epistemic vice. Athens Journal of Humanities and Arts, 2(1), 19-29.

Lahroodi, R. (2007). Collective epistemic virtues. Social Epistemology, 21(3), 281-297.

Linstead, S., Marechal, G., \& Griffin, R. (2014). Theorizing and researching the dark side of organization. Organization Studies, $35(2), 165-188$.

Luzzi, F. (2016). Testimonial injustice without credibility deficit (or excess). Thought: A Journal of Philosophy, 5(3), 203-211.

MacIntyre, A. (1981). After virtue. Notre Dame, IN: University of Notre Dame Press.

Malmendier, U., \& Tate, G. (2009). Does overconfidence affect corporate investment? CEO overconfidence measures revisited. European Financial Management, 11(5), 649-659.

Marcus, A. A. (1987). US firms' responses to regulation: Stonewalling and opportunism. Long Range Planning, 20(3), 98-104.

Matheson, J., \& Vitz, R. (2014). The ethics of belief. Oxford: Oxford University Press.

Mauws, M. K., \& Phillips, N. (1995). Crossroads understanding language games. Organization Science, 6(3), 322-334.

McKinnon, R. (2016). Epistemic injustice. Philosophy Compass, 11(8), $437-446$.

Medina, J. (2013). The epistemology of resistance: Gender and racial oppression, epistemic injustice, and the social imagination. Oxford: Oxford University Press.

Midgley, M. (2001). Wickedness. London: Routledge.

Montmarquet, J. (1993). Epistemic virtue and doxastic responsibility. Lanham: Rowman and Littlefield.

Moore, G. (2008). Re-imagining the morality of management: A modern virtue ethics approach. Business Ethics Quarterly, 18(4), 483-511. 
Morgeson, F. P., \& Hofmann, D. A. (1999). The structure and function of collective constructs: Implications for multilevel research and theory development. Academy of Management Review, 24(2), 249-265.

Munro, I. (2017). Whistle-blowing and the politics of truth: Mobilizing 'truth games' in the WikiLeaks case. Human Relations, 70(5), 519-543.

Nam, D. I., \& Lemak, D. J. (2007). The whistle-blowing zone: Applying Barnard's insights to a modern ethical dilemma. Journal of Management History, 13(1), 33-42.

Nevicka, B., ten Velden, F. S., de Hoogh, A. H., \& van Vianen, A. E. (2011). Reality at odds with perceptions: Narcissistic leaders and group performance. Psychological Science, 22(10), 1259-1264.

Nunan, D., \& Di Domenico, M. (2017). Big data: A normal accident waiting to happen? Journal of Business Ethics, 145(3), 481-491.

Ogden, S. G. (2017). The church, authority, and Foucault. Oxon: Routledge.

Ohlheiser, A. (2016). This is how Facebook's fake-news writers make money. The Washington Post (online). https://www.washington post.com/news/the-intersect/wp/2016/11/18/this-is-how-the-inter nets-fake-news-writers-make-money/?utm_term=.f8910899ec6f.

Oreskes, N., \& Conway, E. (2012). Merchants of doubt. London: Bloomsbury.

Oswick, C., Fleming, P., \& Hanlon, G. (2011). From borrowing to blending: Rethinking the processes of organizational theory building. Academy of Management Review, 36(2), 318-337.

Owen, D., \& Davidson, J. (2009). Hubris syndrome: An acquired personality disorder? Brain, 132, 1396-1406.

Pacepa, I. M., \& Rychlak, R. J. (2013). Disinformation. Medford: WND Books.

Palazzo, G., Krings, F., \& Hoffrage, U. (2012). Ethical blindness. Journal of Business Ethics, 109(3), 323-338.

Parker, M. (2003). Introduction: Ethics, politics and organizing. Organization, 10(2), 187-203.

Paul, P. V. (2017). Fake news, alternative facts, post-truths, misinformation, misinterpretation - and other challenges associated with knowledge generation. American Annals of the Deaf, 162(1), 3-7.

Phillips, N., \& Oswick, C. (2012). Organizational discourse: Domains, debates, and directions. Academy of Management Annals, 6(1), 435-481.

Picone, P., Dagnino, G., \& Mina, A. (2014). The origin of failure: A multidisciplinary appraisal of the hubris hypothesis and proposed research agenda. Academy of Management Perspectives, 28(4), 447-468.

Pritchard, D. (2004). Epistemic luck. Journal of Philosophical Research, 29, 191-220.

Rawwas, M. Y. A., Arjoon, S., \& Sidani, Y. (2013). An introduction of epistemology to business ethics: A study of marketing middlemanagers. Journal of Business Ethics, 117, 525-539.

Rennstam, J., \& Ashcraft, K. L. (2014). Knowing work: Cultivating a practice-based epistemology of knowledge in organization studies. Human Relations, 67(1), 3-25.

Roberts, J., \& Armitage, J. (2008). The ignorance economy. Prometheus, 26(4), 335-354.

Roberts, R. C., \& Wood, W. J. (2003). Humility and epistemic goods. In L. Zagsebski \& M. DePaul (Eds.), Intellectual virtue: Perspectives from ethics and epistemology (pp. 257-279). New York: Oxford University Press.

Roberts, R. C., \& Wood, W. J. (2007). Intellectual virtues: An essay in regulative epistemology. Oxford: Oxford University Press.

Rokeach, M. (1960). The open and closed mind. New York: Basic Books.

Roll, R. (1986). The hubris hypothesis of corporate takeovers. Journal of Business, 59(2), 197-216.
Rupp, D. E., Shapiro, D. L., Folger, R., Skarlicki, D. P., \& Shao, R. (2017). A critical analysis of the conceptualization and measurement of organizational justice: Is it time for reassessment? Academy of Management Annals, 11(2), 919-959.

Russon, M.-A. (2018). Unilever threatens to pull ads from Facebook and Google. BBC News (online). http://www.bbc.co.uk/news/ business-43032241.

Sadler-Smith, E., Akstinaite, V., Robinson, G., \& Wray, T. (2017). Hubristic leadership: A review. Leadership, 13(5), 525-548.

Samuelson, P. L., \& Church, I. M. (2015). When cognition turns vicious: Heuristics and biases in light of virtue epistemology. Philosophical Psychology, 28(8), 1095-1113.

Schön, D. (1983). The reflective practitioner: How professionals think in action. London: Temple Smith.

Solomon, R. C. (1992). Corporate roles, personal virtues: An Aristotelian approach to business ethics. Business Ethics Quarterly, 2(3), 317-339.

Solomon, R. C. (2003). Victims of circumstances? A defense of virtue ethics in business. Business Ethics Quarterly, 13(1), 43-62.

Sosa, E. (1980). The raft and the pyramid: Coherence versus foundations in the theory of knowledge. Midwest Studies in Philosophy, $5(1), 3-26$

Spengler, J. (1972). Social science and the collectivization of hubris. Political Science Quarterly, 87(1), 1-21.

Sperber, D., Clément, F., Heintz, C., Mascaro, O., Mercier, H., Origgi, G., \& Wilson, D. (2010). Epistemic vigilance. Mind \& Language, 25(4), 359-393.

Spicer, A. (2013). Shooting the shit: The role of bullshit in organizations.M@n@gement, 16(5),653-666.

Spicer, A. (2017). Business bullshit. London: Routledge.

Stein, M. (2003). Risk and organizational narcissism at long term capital management. Human Relations, 56(5), 523-540.

Stokes, P., \& Gabriel, Y. (2010). Engaging with genocide: The challenge for organization and management studies. Organization, 17(4), 461-480.

Tanesini, A. (2016). 'Calm down, dear': Intellectual arrogance, silencing and ignorance. The Aristotelian Society Supplementary, XC, $72-92$.

Ten Bos, R. (2007). The Vitality of Stupidity. Social Epistemology, 21(2), 139-150.

Thaler, R. H. (2000). From homo economicus to homo sapiens. The Journal of Economic Perspectives, 14(1), 133-141.

Treviño, L. K., \& Youngblood, S. A. (1990). Bad apples in bad barrels: A causal analysis of ethical decision-making behavior. Journal of Applied Psychology, 75, 378-385.

Trivers, R. (2011). Deceit and self-deception: Fooling yourself the better to fool others. London: Penguin UK.

Vaccari, C. (2013). From echo chamber to persuasive device? Rethinking the role of the Internet in campaigns. New Media \& Society, 15(1), 109-127.

Van Kleef, G. A., Oveis, C., Van Der Löwe, I., LuoKogan, A., Goetz, J., \& Keltner, D. (2008). Power, distress, and compassion: Turning a blind eye to the suffering of others. Psychological Science, 19(12), 1315-1322.

Vince, R., \& Mazen, A. (2014). Violent innocence: A contradiction at the heart of leadership. Organization Studies, 35(2), 189-207.

Wei Choo, C. (2016). The inquiring organization. In How organizations acquire knowledge and seek information. Oxford: Oxford University Press.

Weiss, H., \& Knight, P. (1980). The utility of humility: Self-esteem, information search, and problem-solving efficiency. Organizational Behavior and Human Performance, 25(2), 216-223.

Whyte, W. H. (1956). The organization man. New York: Penguin.

Zagzebski, L. T. (1996). Virtues of the mind: An inquiry into the nature of virtue and the ethical foundations of knowledge. Cambridge: Cambridge University Press. 